in the biological and physical sciences, including engineering, and 300 millions of this will come from the Federal Government. This dependence on Federal support as well as the bias towards science and technology is already disturbing educational authorities, who fear that the heavy bias towards applied science will also destroy the balance between applied and pure science in the universities and seriously affect the teaching staff of American universities. Some estimates of the research effort of American universities in terms of man-power are cited for the physical and engineering sciences and for medical research.

The next two sections of the survey summarize the findings of the Paley Commission and other bodies concerned with the conservation of materials, and the position of the National Science Foundation and the work of the Interdepartmental Committee on Scientific Research and Development. There follows a series of brief reports on progress in atomic energy and nuclear physics; building research and techniques; mechanical and production engineering; computing machines; water supply and treatment; chemistry; metallurgy; fuel and power; and the biochemistry of food processing and preservation. Finally, the technical assistance programme of the Mutual Security Agency is described, although with this only the United Kingdom Scientific Mission is concerned. Among new developments referred to in this report are mortars made with polyvinyl acetate emulsions, a new brick, a method by which concrete slabs for upper floors or flat roofs can be cast at ground-level and jacked into position, a novel lathecutting tool, a "permionic membrane" for giving potable water from brackish or sea water, a continuous ion-exchange process designed by the Stanford Research Institute, the introduction of butadienestyrene latex-based paints and the rapidly increasing use of antibiotics in feeding farm animals.

\section{BRITISH COLONIAL WELFARE AND DEVELOPMENT DURING 1952-53}

A

GLANCE at the "Return of Schemes" made under the Colonial Development and Welfare Acts by the Secretary of State for the Colonies during the period April 1, 1952-March 31, 1953 (Colonial Paper 189. Pp. 26. London: H.M.S.O., June 1953; $1 s .3 d$.), reveals the dependence of Colonial research on the funds provided under these Acts and the importance of the legislation contemplated in the 1954-55 session to which the Colonial Secretary, Mr. Oliver Lyttelton, referred in his statement to the House of Commons on June 24. The schemes detailed in the White Paper bring the total commitments for development and welfare schemes under the Acts to $£ 97,662,196$, of which $£ 13,889,622$ is for the year in question, and for research schemes to $£ 11,710,492$, of which $£ 1,087,041$ is for the year ended. March 31, 1953 . Of this, $£ 372,486$ is for agriculture, $£ 204,878$ for medicine, $£ 204,143$ for insecticides, $£ 119,115$ for products research ( $\$ 41,600$ of which goes to the Colonial Products Research Council), $£ 47,804$ for fisheries, $£ 37,754$ for economic research, $£ 31,330$ for locust control, $£ 23,293$ for tsetse and trypanosomiasis, and $£ 24,088$ for social science.

Of the actual research schemes, the largest are f173,380 for the East African Agriculture and Forestry
Research Organization, $£ 90,000$ for the East African Insecticides Research Unit, $£ 106,597$ for the Medical Research Council's Field Research Station at Fajara, Gambia, and $£ 77,515$ for the Colonial Microbiological Research Institute at Trinidad. $\mathfrak{1} 43,160$ goes to rice research in Nigeria, $£ 43,000$ to the East African Fisheries Research Organization, $£ 32,935$ to the establishment of an Agricultural Research and

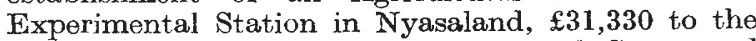
maintenance of the Anti-Locust Research Centre and its extra-mural work, $£ 29,321$ to the East African Institute of Social and Economic Research, $£ 26,450$ to the Hot Climate Physiology Unit in Nigeria, $£ 24,000$ to malaria research in Trinidad, $£ 19,200$ for research into the control of Stomoxys calcitrans in Uganda, and $£ 16,900$ for fundamental insecticide research at the Silwood Park Station (Imperial College of Science and Technology, London) and at Rothamsted Experimental Station.

Grants of particular scientific interest for development and welfare schemes, apart from those for geodetic, topographical, geological and mineral surveys, include $£ 29,476$ for the control of 'sudden death' disease of cloves in Zanzibar, $£ 185,000$ for a scholarship scheme for residents in Colonial territories to provide training to qualify for public service, $£ 121,620$ to University College, Ibadan, $£ 108,040$ for the development of African education, and substantial grants for the improvement or development of roads in Nyasaland ( $£ 220,000)$, Malta ( $£ 364,394)$, North Borneo $(£ 305,900)$ and British Guiana $(£ 315,416)$, and for the improvement of water supply or control in British Guiana (£919,481), the Gold Coast $(£ 488,000)$, Malta $(£ 320,250)$ and Gambia $(£ 70,000)$. Of a further $£ 1,230,000$ for the Uganda Development Plan, $£ 180,000$ is for geology and rural water supplies, $£ 390,000$ for education, $£ 120,000$ for medical schemes, $£ 150,000$ for urban water supplies and $£ 90,000$ for agriculture.

\section{UNIVERSITIES' COUNCIL FOR ADULT EDUCATION REPORT FOR $1951-52$}

YNIKE the previous six annual reports of the Universities' Council for Adult Education, the seventh annual report, covering the year 1951-52, attempts to survey the extra-mural work of the constituent universities as a whole*. During the year, the work of University Extra-mural Departments throughout Great Britain further expanded, and the departments in the Council became more closely associated. With the addition of the Universities of Edinburgh, Glasgow and Belfast, the membership of the Council is now twenty-one, and the number of courses and classes conducted was 4,064, as compared with eighteen and 2,067, respectively, during 194546. During the 1951-52 session, two committees completed their investigations into the teaching of science and the training of teachers, respectively, while the up-to-date bibliography of adult education and the handlist of current studies in the subject, prepared by the Council's Research and Training Sub-Committee, were published, as a co-operative enterprise, by the National Institute of Adult Education.

* Universities Council for Adult Education. Report on the Year 1591-1952. Pp. 26. (Bristol: W. E. Salt, Hon. Secretary, The University, Bristol, 1953.) n.p. 
Apart from its interest in relation to the review of adult education which is now going on, the report records the activities of the last session of the first post-war quinquennium, a period marked by striking advances in extra-mural work; and it appears at a time when further development has received its first check, through economies imposed by the universities themselves. The report is thus of value as a contribution to the stocktaking and reconsideration, in the light of recent experience, of possible lines of development, which are appropriate at the outset of a new quinquennium. The Council suggests that a stage of consolidation has now been reached after the rapid expansion of the post-war years ; but it does not expect that consolidation will be possible at the peak of achievement. The warning that checks to the growth of adult education, mechanically applied, may have unforeseen and far-reaching consequences, and that interrupted development cannot be resumed at short notice, is the more impressive for the restraint with which it is expressed.

Nevertheless, the report points out, the universities of Great Britain are entering upon a period of great difficulty with greater strength in resources and reserves than at any previous terms. Apart from the increase in extra-mural staffs, the improvement in their conditions of service, and the greater support of the departments from their universities, grants from the Ministry of Education have increased from $£ 71,000$ in $1938-39$ to $£ 265,000$ in $1951-52$, an increase which reflects the encouragement given to adult education through the application of the principles of the Education Act of 1944. Much has also been due to the interest and encouragement of the Ministry of Education and its officers.

The debate on the scope, purpose and organization of liberal adult education continues unabated, and many of the reports on the session's work are marked by critical examination of the function and contribution of university adult education, having regard to the economic position of Great Britain. Generally the reports indicate an increasing concern with standards of work and an increasing response by the more serious students to the demands made upon them. While every extra-mural department has been paying increasing attention to standards of work, the figures show a slight decline, on averages, from previous levels, and it appears that here, and elsewhere, there is a greater range of performance than usual between the good and the less satisfactory students. Moreover, while the number of classes in Great Britain has greatly increased, the average enrolment in classes has decreased, and it appears to be more difficult to recruit students for long courses of study.

A distinctive feature of liberal adult education in Great Britain has been its rejection of patently utilitarian studies ; but there are indications that in certain subjects-notably the social sciences and industrial relations - the offer of a qualification might stimulate demand. Examinations and qualifications, however, are exceptional features of extra-mural work, though, at least in longer courses, serious work is expected of students, and it is a tribute to their zeal that so much should have been done.

As regards present difficulties, the report suggests that conditions of full employment are not conducive to wide interest in adult education among manual workers. While radio and television are probably its strongest rivals, television is not regarded as necessarily harmful to adult class-work. More use could probably be made of both television and soundbroadcasting as supplements to class teaching, and some questioning of the traditional methods of both organization and teaching is reported. There are signs that different approaches are already being made; but the traditional type of course is provided for the kind of student which is the particular concern of the Workers' Educational Association. The tutorial class was originally devised as a preliminary training for 'workers' deprived of any chance of more than merely elementary schooling, who wished to prepare themselves for the discipline of a course of university study. It rapidly became a substitute for both secondary and higher education for all those whose schooling had been restricted, and as such did notable work. It has now also become a course of study for those who have had reasonable educational opportunities, but who wish to take their education further or pursue some particular interest or study under guidance. The report gives no suggestion as to the Council's own views concerning the decisions which should be taken if economy enforces re-orientation or re-organization of extra-mural work. It indicates, however, that the university departments are fully alive to the issues involved, and the figures given in this report and its survey of subjects of study should materially assist an objective appraisal of the scope and functions of extra-mural work and adult education in the new context.

\section{CARNEGIE UNITED KINGDOM TRUST \\ REPORT FOR 1952}

IN spite of continuing restrictions on capital 1 expenditure, the thirty-ninth annual report* of the Carnegie United Kingdom Trust for 1952 reports good progress with several projects which involved building, notably for the rehousing of the Scottish Central Library and the provision or improvement of village halls. A building licence has also been granted for the Cheshire Foundation Home for the Sick, and it is hoped that the erection of a completely new home, specially designed for its purpose, and which may serve as a model for similar social enterprises elsewhere, will now proceed. A licence has also been granted for the boys' home to be provided by the West Ham Central Mission, and work started in November on this experiment with a country home for boys who had been in trouble or were likely to run into it. Grants during the year totalled $£ 112,667$, and the Trust work now appears to be proceeding on an adequate scale after the straitened years of the Second World War. In continuance of earlier surveys of juvenile delinquency, the Trustees have appointed Mr. John Mack, Stevenson lecturer in citizenship in the University of Glasgow, to make a survey of agencies active in this field and the difficulties which confront them. Mr. Mack was particularly asked to direct attention to any gaps in existing services and to indicate any effective action the Trustees might take by initiating genuinely pioneer work, whether preventive or remedial. Pending this report, the Trustees have already concluded that their most effective contributions will be found in their traditional field of practical experiment and demonstration. * Carnegie United Kingdom Trust: Thirty-ninth Annual Report, 1952. Pp. 32. (From the Trust, Dunfermline, Fife.) 